\title{
Hey Garvin! Science is a game: A reply to McCain, Ward, and Lobb
}

\author{
STEPHEN F. DAVIS \\ Austin Peay State University, Clarksville, Tennessee 37040 \\ ROBERT E. PRYTULA \\ Middle Tennessee State University, Murfreesboro, Tennessee 37130 \\ and \\ JOHN D. SEAGO \\ Concord College, Athens, West Virginia 24712
}

\begin{abstract}
Several of the points raised by McCain, Ward, and Lobb are considered in an attempt to better understand the variety of results that have been obtained in magnitude of reward experiments. Data from a magnitude of reward study are presented in which: (1) magnitude effects are found early in training (start measure), (2) magnitude effects are NOT found (run measure), and (3) magnitude effects are found that persist throughout the course of the 56 trials administered (goal measure). These results point to the complexity of the phenomenon under investigation and suggest the need for continued research.
\end{abstract}

As McCain (1971) has pointed out, "It is always gratifying to know that there are those out there who read, even disapprovingly, your written efforts" (p. 14). By and large, the points raised by McCain, Ward, and Lobb concerning the Marrero, Davis, and Seago (1973) study are well made and serve to bring into bold relief the state of confusion that currently exists in the area of reward magnitude effects. However, several of these points do, we feel, merit some discussion.

First, we would certainly agree that "it would be foolhardy to do other than give rough approximations" concerning the point in training at which reward magnitude effects might be expected to disappear. This would appear to be especially important in view of their statement that "In practice we have seen the group differences disappear anywhere from approximately 10 trials to about 100 trials." Hence, as only 50 training trials were employed, we would agree that the results of the Marrero et al. (1973) study are not a completely adequate test of the reward magnitude phenomenon. The results of that study were intended, however, to reflect the position that reward magnitude may, at least in some situations, be an influential determinant of performance. A recent study reported by Davis, Harper, and Seago (1975) possibly reflects this viewpoint somewhat more concisely. In this study, three groups of rat subjects

This research was supported by a Tower Fund research grant from Austin Peay State University to the first author and a faculty research grant from Middle Tennessee State University to the second author. The title of this paper is intended to convey the notion that scientific endeavor can, in fact, be challenging and often perplexing. These feelings are well described in The Game of Science by McCain and Segal. received single-pellet large reward (one 500-mg pellet), multiple-pellet large reward (11 45-mg pellets), and small reward (one 45-mg pellet), respectively, during the course of a 51-trial acquisition phase. The results indicated that reward magnitude effects developed and persisted to the conclusion of this phase. The authors concluded that "Had Phase I of the present study been extended beyond 51 trials, it is quite possible that the observed magnitude effects would have eventually dissipated." It would appear, then, that reward magnitude effects may or may not develop. Unfortunately, the nature of the factors influencing this phenomenon would appear to be quite elusive at present. A range of values from 10 to 100 trials where magnitude effects have been observed to dissipate would be indicative of this elusiveness.

Second, other points raised by McCain et al. might be mentioned at this point. It was pointed out that studies by Black (1969) and Campbell, Batsche, and Batsche (1972) have been reported in which satiation effects were taken into account and reward magnitude effects failed to develop. We again would agree with McCain, Ward, and Lobb that it is nice "to have a colleague in another laboratory examine the possible effects of satiation." On the other hand, it would not appear to be inappropriate, as Marrero et al. (1973) state, "to investigate possible reward magnitude effects in a situation where the reward magnitude for large-reward subjects and the number of trials per day were not as great as in the McCain $(1969,1970,1971)$ and Daly (1972) studies" (p. 375). Incidently, the citation of McCain (1969) was included because, as is indicated in that paper, "The results pose a problem of interpretation in reward 
magnitude studies" (p. 2). Concerning the "unique" degrees of freedom reported by Marrero et al. (1973), here we must plead guilty! It is indeed puzzling to encounter four groups of five subjects each and 1 and $19 \mathrm{df}$ for an interaction. However, when one recognizes that the $F$ values concerned were, in fact, evaluated at 1 and $16 \mathrm{df}$ and that a typographical error was involved, the matter, happily, resolves itself.

Third, concerning the lack of reward magnitude effects on the part of the large- and small-reward anosmic subjects in the Marrero et al. (1973) study, possibly "elimination" was a somewhat strong ad-hoc assumption, but it does describe the data of that particular study. It is interesting to note that similar results have recently been reported by Davis et al. (1975). Taken as a whole, then, the three studies using surgically anosmic subjects conducted in our laboratory (i.e., Davis \& Seago, 1975; Davis et al., 1975; Marrero et al., 1973) suggest, rather strongly, that one effect of anosmia is to reduce incentive motivation.

Finally, the general topic of transformation of data and measures taken would also appear to merit some consideration. Here again one encounters a bewildering state of affairs!. First, there are studies (e.g., Daly, 1972; Davis et al., 1975; Marrero et al., 1973) which have reported transformed data that have been supportive of reward magnitude effects, at least to the extent of the number of trials reported. Second, there are studies (e.g., McCain, 1970) which have not reported transformed data which have not been supportive of reward magnitude effectiveness. Lastly, there are the results reported by McCain, Ward, and Lobb using transformed data that are not supportive of reward magnitude effectiveness. Coupled with this is the problem of the type of measure that has been reported. Literally all of the measures taken in the straight runway situation (i.e., start, run, goal, and total time or speed) have been reported. Obviously, such a wide variety of data and measures are the prime breeding ground for inconsistencies. The study to be reported was designed to further investigate some of these problems and inconsistencies.

\section{METHOD}

\section{Subjects}

The subjects were 20 naive male albino rats purchased from the Holtzman Company, Madison, Wisconsin. All subjects were approximately 90 days old at the beginning of the experiment.

\footnotetext{
Apparatus

The apparatus (more fully described in Davis et al., 1975) was a single straight runway divided into a $38.10-\mathrm{cm}$ gray startbox, a $91.44-\mathrm{cm}$ black run section, and a $30.48-\mathrm{cm}$ black goalbox. Start, run, and goal times were recorded on all trials.

\section{Procedure}

Upon receipt from the shipper, the animals were randomly assigned to two equal groups: L (large reward) and S (small
}

reward). Two weeks prior to the beginning of the experiment proper, all subjects were placed on food deprivation and were maintained at $85 \%$ ad-lib body weight during the course of the experiment. The 6 days immediately preceding the inception of the experiment proper consisted of pretraining for all subjects. During pretraining, the subjects were handled and tamed (Days 1-4), allowed to explore the unbaited apparatus for $5 \mathrm{~min}$ (Days 5-6), and habituated to the appropriate reward pellets in the home cage (Days 1-6). A 56-trial acquisition phase (two trials per day) immediately followed pretraining. During this phase, subjects in Group L received one 500-mg Noyes pellet per trial, while subjects in Group $S$ received one $45-\mathrm{mg}$ Noyes pellet per trial. The order for running subjects was randomized daily.

\section{RESULTS AND DISCUSSION}

Figure 1 presents mean start, run, and goal-speeds (meters per second) for Groups $\mathrm{S}$ and $\mathrm{L}$ during the course of the 56-trial acquisition phase. Groups by trial blocks (1-14) analyses of variance performed on this data indicated that a significant trial blocks effect, $F(13,134)=5.06,6.22,4.64, p<.01$, existed for the start, run, and goal measures, respectively. The Groups by Trial Blocks interaction was found to be significant in the start, $F(13,134)=7.57, p<.01$, and goal, $F(13,134)=2.03, p<.05$, measures. The groups factor was found to be significant, $F(1,18)=$ $9.23, \mathrm{p}<.01$, in the goal measure. Simple main effects analyses, used to probe the significant interactions,

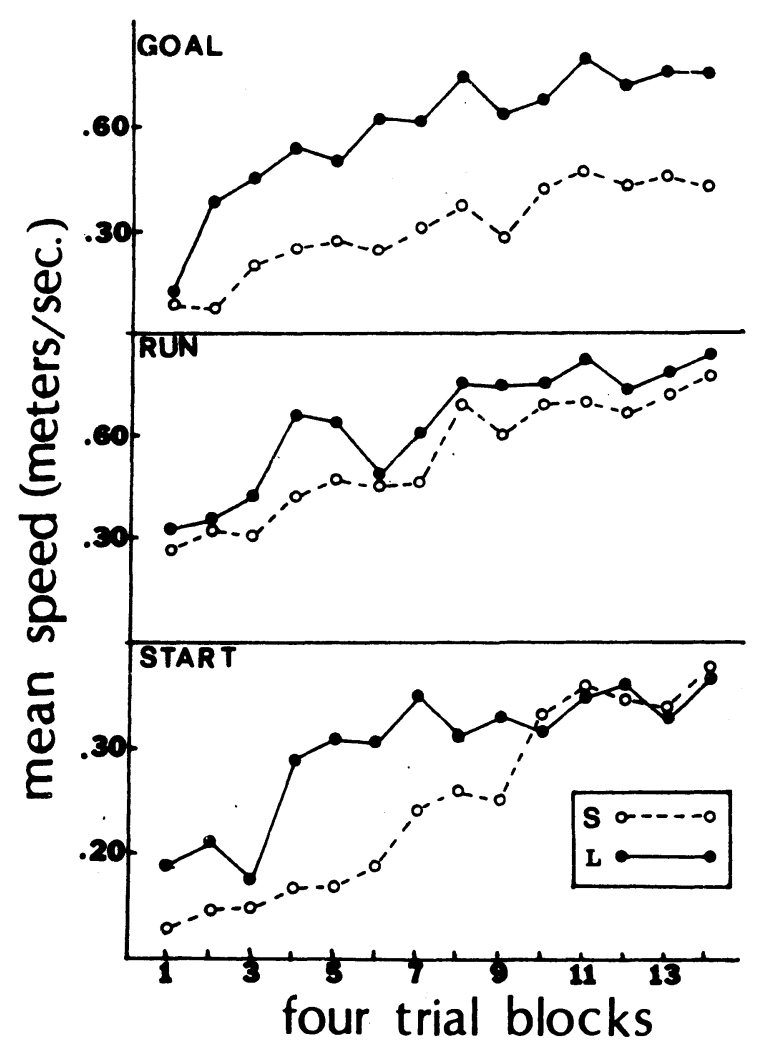

Figure 1. Mean start, run, and goal speeds (meters per second) for Groups $S$ and $L$ during acquisition. 
indicated that Groups $\mathrm{S}$ and $\mathrm{L}$ did not $\operatorname{differ}(\mathrm{F}<1)$ at Trial Block 1 in the goal measure. All other differences between the groups in this measure achieved significance $(p<.05)$. Significant $(p<.05)$ differences between Groups $S$ and $L$ were found at Trial Blocks 4-7 in the start measure.

Depending upon which measure one's attention is directed toward, it would appear that seemingly different interpretations could be generated by the results of the present study. For example, if one chose to concentrate on the start measure, there is supportive evidence for the development of magnitude effects early in training and their dissipation as training progressed. On the other hand, if just the run measure was consulted, a case could well be mustered for the lack of any reward magnitude effects. Conversely, if the goal measure is the focus of attention, a case supportive of reward magnitude effects (at least throughout the course of the 56 trials that were administered) could be made. Of course, one could speculate as to what would emerge if a measure such as total time or speed was reported.

Rather than suggest that any one of the above viewpoints is THE correct one, we would propose that the data from the present experiment are indicative of the complexity of the phenomenon under investigation. At this point, it would seem fruitless to continue to debate whether or not reward magnitude effects are, in fact, genuine. The data that has accumulated would indicate that the answer is yes (under certain conditions) and no (under certain conditions). It would appear to be more profitable, on the other hand, to pay heed to McCain's (1971) suggestion that "Perhaps in desperation we should go back, or just go, to the laboratory" (p. 15). Only there will the specific factors involved in this phenomenon make themselves known.

\section{REFERENCES}

BLACK, R. W. Incentive motivation and the parameters of reward in instrumental conditioning. In W. J. Arnold and D. Levine (Eds.), Nebraska symposium on motivation. Lincoln: University of Nebraska Press, 1969.

Campbell, P. E., Batsche, C. J., \& Batsche, G. M. Spacedtrials reward magnitude effects in the rat: Single versus multiple food pellets. Journal of Comparative and Physiological Psychology, 1972, 18, 360-364.

DALY, H. B. Learning to escape cues paired with reward reductions following single- or multiple-pellet rewards. Psychonomic Science, 1972, 26, 49-52.

Davis, S. F., \& Seago, J. D. Differential conditioning as a function of surgical anosmia. Bulletin of the Psychonomic Society, 1975, 6, 10-12.

Davis, S. F., Harper, W. E., \& SEago, J. D. Runway performance of normal, sham, and anosmic rats as a function. of magnitude of reward and magnitude shift. Bulletin of the Psychonomic Society, 1975, 6, 367-369.

Marrero, B., Davis, S. F., \& Seago, J. D. Runway performance of normal and anosmic rats as a function of reward magnitude: A preliminary report. Bulletin of the Psychonomic Society, 1973, 2, 375-376.

McGain, G. Different levels of performance with equivalent weights of reward. Psychonomic Science, 1969, 14, 2-3.

McCaIN, G. Reward magnitude and instrumental responses: Consistent and partial reward. Psychonomic Science, 1970, 19, 139-141.

McCaIn, G. Traupmann and Wong: A reply. Psychonomic Science, 1971, 23, 14-15.

McCain, G., Dyleski, K., \& McElvain, G. Reward magnitude and instrumental responses: Consistent reward. Psychonomic Monograph Supplements, 1971, 3(16, Whole No. 48).

(Received for publication October 17, 1975.) 